The Teaching of Scholarship Mathematics in Secondary Schools

Author(s): W. P. Milne

Source: The Mathematical Gazette, Vol. 7, No. 104 (Mar., 1913), pp. 80-86

Published by: Mathematical Association

Stable URL: http://www.jstor.org/stable/3603857

Accessed: 23-10-2015 12:27 UTC

Your use of the JSTOR archive indicates your acceptance of the Terms \& Conditions of Use, available at http://www.jstor.org/page/ info/about/policies/terms.jsp

JSTOR is a not-for-profit service that helps scholars, researchers, and students discover, use, and build upon a wide range of content in a trusted digital archive. We use information technology and tools to increase productivity and facilitate new forms of scholarship. For more information about JSTOR, please contact support@jstor.org. 


\section{THE TEACHING OF SCHOLARSHIP MATHEMATICS IN SECONDARY SCHOOLS.}

Ir was considered only natural, a generation or two ago, for the schoolmaster to make it his first business to teach the clever boys, and then to give some attention to his less gifted pupils if he had sufficient time and energy left. Furthermore, a large proportion of what was taught was entirely beyond the comprehension of any but the abler boys. For the last twenty or thirty years a movement has been in progress so to devise schemes of knowledge and methods of imparting it that the rank and file of the pupils in a school shall be able to take full advantage of the instruction given. The result of this psychological study and investigation has been that never before have the imparting of knowledge by the teacher on the one hand and the assimilation of it by the pupil on the other been so well understood as they are at the present day. Though there may be disagreement as to details, there can be no doubt of the great advance made.

On the other hand, there are in every Secondary School some distinctly clever boys-lads of more powerful comprehension and penetrating intelligence than the average pupil. Nothing could be more disastrous to the intellectual well-being of our nation than that the capacities of these students should not be trained up to their highest pitch. They are capable of it, and have therefore the right to it. Some Secondary Schools are unable to give this specialized training for financial reasons. It means a larger staff. But there lurks in the headmaster's mind a hope-or shall we call it an ambition-that some day in the future the funds may be forthcoming which will enable him to deal adequately with his clever boys. The proper training of these able pupils is the most important contribution that our Secondary Schools have it in their power to make towards the maintenance of Great Britain's intellectual position among the nations.

It is needless to remark that the paths followed up by these clever pupils are various and diverse. But a large proportion of them are being trained to compete for scholarships at the Universities, and it is with these we shall deal more particularly here. It has to be noted that for many years past the best pedagogic thought of the country has been directed towards devising methods of teaching the generality of the pupils, while very little has been done to modify or improve the course of instruction given to the scholarship candidate. He has, in fact, been obscured by the clamant needs of the average pupil. The result is that, in the republic of the Secondary School, the status of the scholarship boy was never so low as it is at present, and yet he is the man who for the most part is being trained to lead in the various activities of the nation in his after-life.

Let us assume then that we are dealing with schools whose finances permit them to give special training to the scholarship candidate. The question that next arises is, "What are to be our aims in our teaching of scholarship work?" The answer to that seems to be: There exists a well-defined schedule of mathematical knowledge with sufficiently elastic boundaries which we are expected to impart to scholarship candidates. Within these limits we ought to avail ourselves of the most up-to-date knowledge and methods of the subject. Furthermore, we ought not to teach the subject as though a brick-wall surrounded the schedule, over which no schoolmaster and no schoolboy could possibly climb. The feelings so produced in both teacher and taught are akin to those which a Highland poet has described as existing in his native village before the institution of the annual cheap railway fares to Edinburgh. He sings 
of the surprise which his fellow-villagers exhibited when they first discovered for themselves that

\footnotetext{
"The warld gangs a' the way tae Edinburgh Toon, An' stretches further still."
}

We ought to teach our pupils that the mathematical world goes all the way to the edge of the schedule and stretches further still.

Again, what is to be the supreme test of the successful teaching of scholarship work? Is it to be whether or not the boy obtains a scholarship at the University? Surely we have passed that stage long ago with regard to the elementary work in the school. Why should we continue to uphold it with regard to the advanced work? It is undoubtedly one test, and a good test, of whether or not a boy possesses a competent knowledge of the range of work prescribed, but it is not the only test. There can be no doubt that if heads of mathematical departments, etc., were to apply the same stringent canons of criticism to the teaching of the scholarship work as they do to the elementary work, a sad tale would be unfolded throughout the country. The same standard of craftsmanship is not demanded by public opinion from the teachers of scholarship work as is required from the teachers of the less advanced subjects.

But some may maintain that this is unnecessary, that the boys being abler can be left more to themselves and learn more by themselves. To a certain extent this is true, but the boys have to learn what they do not learn from the teachers out of the text-book, and we all know that owing to the labour of preparation and the small pecuniary returns, text-books covering the ground of scholarship work are rarely published, and continue to be used when long out of date. Now few boys can rediscover for themselves the theorems of the great masters. They have to be taught them. In fact, the following dictum of Sir William M. Ramsay in a paper on "Classical Research" approximately sums up the situation also with regard to the teaching of the higher mathematics in a Secondary School: "It is the fact that if the young classical researcher is to do good work, half the labour and three-fourths of the thought must come from his trainer. The pupil does the labour for himself, as he thinks, but the trainer also does it, and so is able to keep him in the straight path.",

Our object in scholarship teaching ought to be to lay a solid foundation, so that the University teachers may proceed to build at once their superstructure thereon. For that reason the teaching should be sound, so that nothing has to be unlearned when the student proceeds to College. Also, the teaching at School and University should be as far as possible continuous. A careful observation of existing conditions leaves no doubt that much unnecessary dislocation exists when a pupil passes from the Secondary School to the University. I can remember a student who informed me that he had never passed through a time of such intellectual misery in his life as he did in his first term at the University. He had been taught the Calculus at school by what a well-known mathematician has called "the method of pictures and plausibility." He then entered the University, and began straight away the rigorous study of analysis. The formal definition of a limit-so different from what he had been taught at school, what the whole subject was trying to "get at," and above all the sight of the fabric of the Calculus he had learned at school tottering at its base and threatening to crumble to ruin-nearly drove him crazy. He did not know where he was. He dreaded the future, for he had lost confidence in the past. In fact, the abrupt change from the "hail-fellow-wellmet " treatment of limits at the schools to the rigorous treatment with 
the inevitable $\epsilon$ at the Universities was such an insuperable barrier to many students that some years ago analysis bore--and perhaps still bears -amongst students the name of "Epsilonology," and acquaintance with it was regarded as a terrifying experience. The explanation of this phenomenon is simple. The fundamental conceptions of analysis (such as irrational numbers, complex numbers, sequences, etc.) receive no adequate treatment at the Secondary Schools because they will be taught at the Universities, and they receive no adequate treatment at the Universities because they have been taught at the Secondary Schools. Hence they are not explicitly discussed at all. Again, the text-books present the same state of affairs. The elementary text-books in general present the fundamental laws of algebra (the law of signs in multiplication, the laws of commutation, association and distribution, etc.) as though they had dropped from the skies, on the ground that their philosophical explanation is too difficult for some pupils. The more advanced treatises assume that they have been already adequately treated in the elementary books. The only book with which I am acquainted that attempts to present the philosophical side of the fundamental laws so as to be understood by scholarship candidates is the Arithmétique of Jules Tannery, the great French mathematiciall. To give an illustration of the lacuna that exists at this stage of the pupil's mathematical training, I may quote from the preface of the Cours d'Analyse by Goursat:

"Mathematical Analysis being essentially the science of the continuous, it seems that logically every course of Analysis ought to commence with the study of irrational numbers. I have, however, supposed this notion acquired. The theory of incommensurables is treated in excellent and well-known works, and in such a masterly manner that it seemed to me unnecessary to go over the ground again." Now every student knows that Goursat is just the book he wants on Analysis at the beginning of his University career, but its usefulness is sadly impaired by the fact that our schoolboys are not, in general, being prepared on up-todate lines so as to be able to appreciate it. We still teach with great dignity and detail the method of finding the greatest term in the Binomial Expansion, while it is no exaggeration to say that not fifty per cent. of the candidates who could write out a faultless essay on the above theorem have a clear notion of the difference between a rational and an irrational number, or could quote the simplest instance of a property possessed by irrationals which is not also possessed by the rationals.

When any state of affairs is unsatisfactory in the teaching world, it is customary to throw the blame on the external examiner. In the case of scholarship work the external examiner cannot in most cases be blamed. $\mathrm{He}$ has ceased to regard the manipulative faculty as the sole test of mathematical proficiency. He has discarded artificial questions, and now sets natural ones; he sets essay papers to test whether the candidates have enquired into or even thought about the fundamental ideas of the subject, whether they can take a comprehensive view of a branch of mathematics and show in essay form the main theorems, and what they are each and all "getting at." What more can we teachers desire? What now remains for those who work in Secondary Schools is to bring the teaching more into line with the most up-to-date trend of mathematical thought. We want reform but not revolution. We want improvement in the various portions of the subject which we teach, but we want still more to improve the spirit of the whole schedule of knowledge which we are called upon to impart. Thus Theory of Functions looms large in the future of our pupils : is it not imperative that the teaching of algebra should be moulded towards that end? Is the Theory of Probability and 
Diophantine Equations essential knowledge on the part of a pupil who does not know what an irrational number is?

The following are one or two points which are worthy of consideration:

(1) A celebrated mathematician-Salmon I think it was-has said that if a tithe of the time now spent in finding the areas of dreadful circles inscribed to dreadful triangles self-conjugate to dreadful conics were devoted to the application of that complicated analysis which is required for Cubic Curves, the pupils would receive the same drill in manipulative analysis and, in addition, a knowledge of more geometry than they at present possess. I have no wish to advocate the inclusion of Higher Plane Curves into the scholarship syllabus, but the principle contained in the above pronouncement ought to have our whole-hearted sympathy. There are many really important developments in the geometry of conics that required high manipulative faculty, such as the theory of the $F$ and $\Phi$ conics and many loci connected therewith. The geometry of the triangle and its circles offers a large field of investigation on which our pupils could practise harder analysis and learn something more about geometry at the same time.

(2) Another noted mathematician has said that it is easier to learn the Calculus than methods of avoiding it. We all remember what a cumbrous business it used to be to find the centre of pressure of a triangular lamina, etc., by means of infinite series. Again, the proofs of the "Potential Energy $=\frac{1}{2} \Sigma E V$ " in Sir J. J. Thomson's Elements of the Mathematical Theory of Electricity and Magnetism is at least as hard on its algebraic side as it is on its physical, inasmuch as the prevailing state of mathematical tradition at the time when he wrote the book precluded a whole-hearted use of the Calculus. That is all gone now, but many disabilities of the same kind still remain. Our scholarship candidates actually use in many instances harder methods of applying a given formula than would the experts in the subject in dealing with the same formula. One has only to take the case of summation-diagrams. The application of graphical methods to the proofs of those betes-noires of our student days, the Binomial, Exponential, and Logarithmic Expansions, renders their rigorous demonstrations much more easy, as the pupil sees laid out before his eyes in panoramic form the numbers with which he is dealing. No one would nowadays, when cartridges have been invented, dream of sending forth an army armed with muzzle-loading guns and powder flasks and funnels and ram-rods. Why do we use "flintlock" methods in mathematics?

(3) The choice of a clear notation is of importance in our mathematical text-books. Several of our learned societies, in order to cheapen the cost of publication, have been compelled to simplify, from the printer's point of view, the notation used. (Thus it is easier to print $p / q$ for $\frac{p}{q}$ and $n$ ! for $\mid n$.) But though this form of notation presents no obstacle to mature experts in the case of the learned societies, it is a very different matter with the scholarship candidates in our Secondary Schools. What is a simplified notation for the printer is not generally a simplified notation for the student. We need only quote the case of Chrystal's Algebra. The usefulness of that great book has been greatly diminished by the notation used. It is often a matter of considerable difficulty to comprehend at a glance the import of a formula in that work, and though the student may struggle once to see what a complicated expression means, he cannot be expected frequently to interrupt his study of a difficult argument to master mere difficulties of the eye. The interests of the young student must not be sacrificed to those of the printer. 
(4) Again, more attention should be paid to teaching fundamental ideas. Things are better in this respect than they used to be, as may be seen from a historical glance at the teaching of "infinity" and "imaginaries" in geometry. A man who in his day had been one of the first six wranglers found that in his declining years he had to teach about this new thing called " infinity." He said quite frankly, "Things at Infinity are bad enough, but when you get imaginary things stowed away at Infinity, it beats my comprehension." Teachers of the last generation had clearer notions on Infinity, and taught that "There is a happy land, far, far away," and its name is Infinity. But the idea had crystallized into a definite shape when a noted Cambridge teacher defined the imaginary Circular Points at Infinity as the two old extinct windmills at Shelford and Trumpington respectively. The designation of these points by $I$ and $J$ and their subsequent baptism as Isaac and Jacob mark the final stage in the evolution of the accurate teaching about these once mysterious Circular Points at Infinity. It behoves teachers, therefore, to introduce the fundamentals of mathematics to our pupils in a less haphazard way.

(5) I have frequently found the following method of teaching a subject useful. Instead of asking the pupils to read the bookwork, I cyclostyle papers containing the bookwork broken up into easy problems, each following after and depending on the one in front. In this way the pupil discovers a good deal of the bookwork for himself, and is stimulated and exhilarated thereby.

That many teachers are dissatisfied with the prevailing state of affairs with regard to the teaching of scholarship work cannot be doubted. Thus I had a note from Mr. W. J. Greenstreet this term deploring the fact that tangential coordinates receive such scanty attention throughout the Secondary Schools of this country, while I had recently a long letter from Mr. G. W. Palmer referring to the chaotic state of the teaching of complex numbers, infinite series, etc. My suggestion then is this. Would it not be desirable that the Mathematical Association should appoint a committee to go into the whole question of scholarship teaching, and make a full report thereon? Surely it is the proper body to take in hand a most important, pressing, and difficult piece of work.

The President invited remarks on Dr. Milne's paper.

The Rev. E. W. Barnes : I should like to say that I have seen the work of a fairly large number of scholarship candidates soon after they have come up to the universities in recent years, and that I think Dr. Milne takes an unduly pessimistic view of the present situation. I am inclined to think that not only have the text-books improved, and that there has been a marked advance in accuracy and range during the last twenty years, but also that the teaching of the candidates at the schools. has steadily improved, so that now the boys come up, many of them knowing accurately a number of things which are surprising to those of us at Cambridge, who know the labour which must be expended before such success is gained. Thus, my own impression is quite different from that which the present situation appears to have left on Dr. Milne's mind.

The President: I should like to corroborate what Dr. Barnes said. No doubt some of the books at the universities, when the new methods were introduced, were ahead of the schools. But that was inevitable. It took some time before the new ideas were taught in the schools, because the teachers had been brought up themselves among the old ideas of teaching the calculus and so forth. To expect a completely different standard in methods of teaching in a short time was to expect 
the accomplishment of a very difficult thing. But now a sufficient number of years have passed for a new generation of teachers to have arisen, and these have actually succeeded in doing a great deal towards introducing the class of boy under discussion to newer ideas. I have noticed during the thirty or more years in which I taught general mathematics at Cambridge that there was a regular improvement in the conceptions of mechanics on the part of boys who came from school. In the early part of that time they were brought up on old books such as Parkinson's Mechanics, but as soon as Dr. Garnett's book appeared a great change was produced. At first things moved somewhat slowly, but within ten or fifteen years there was a very marked increase in the number of boys who really did know something about the principles of mechanics, especially as to what the quantities involved were. I noticed during the whole of those years that there was a considerable steady, though slow, improvement in that way, and I attribute it mainly to the change that was brought into the schools by a new generation of teachers who had learnt something at the universities, and who brought these new ideas gradually to bear on their school teaching; and I imagine that, as regards the foundation of pure mathematics, the calculus in particular, a good deal of such influence must be seen in that case too. In fact, one has only to be at the meetings of this Association to become aware of the fact that there are a considerable number of teachers of mathematics in the schools who are fully acquainted with all the modern ideas in connection with these subjects, for instance, that the doctrine of limits must in some form or other be placed at the base of all treatments of the calculus. That is fully appreciated by all in this Society who take part in the discussions, so that we may take it that something has been gained. No doubt there are schools, and there are teachers in schools, that still lag behind; but they are being gradually eliminated, and I think we may look forward in the hope that they will be still more fully eliminated in the future.

I was very glad to hear the importance emphasised of attention to this class of boys in schools. It is, I feel as strongly as any one, our main business to improve the teaching of what I venture to call the intellectual democracy. That is a most important task which ought not to be neglected. But at the same time we have got to remember that the torch of science has been, and always will be, carried forward by the few and not by the many, and it is of the greatest importance, as was emphasised by the speaker, that we should not, in our enthusiasm for dealing properly with the rank and file, go so far as to allow the teaching of the best class of student to deteriorate. I think there is some possibility of their being partly, if not wholly, neglected, while we are devoting our attention to the teaching of the great body of students. I think it is always difficult to keep one's attention on two things at the same time. Whatever attracts one's attention for the time being seems the most important. We have to remember that there are other things just as important, which we must not neglect. We have had to attend of late years to the teaching of the average boy and girl, but we must not forget that there are others who do not belong to the average, and that their teaching must not be neglected. I was very pleased indeed to hear that point emphasised by Dr. Milne.

The President announced that Mr. Siddons would give a brief account of the work of the Committee.

Mr. Siddons : This has only just been sprung on me at a moment's notice. I think members of the Association will be interested to hear that the Committee are not merely sleeping. The Special Committees have all got to work, and they are considering, though they have not yet 
published, Reports on the general curricula in the particular kind of schools with which they are concerned. The Gereral Committee has had a very busy time in connection with examination papers and examination schedules. I may say that within the last month or two, two bodies have received, or are just going to receive, our proposals. I think it is a thing that we may be distinctly pleased about-that two important examining bodies are willing to consider our suggestions. Further than that, one important examining body proposed to set a new paper in the course of last year, and they very kindly listened to many suggestions that we had to make in regard to a proposed specimen paper, and when the specimen paper was published, it was seen that they had made many changes in the paper in accordance with our recommendations.

We are doing what we can to keep in touch with the examining bodies, and hope to do still more in the next twelve months. I say this request. is only sprung upon me at a moment's notice, and I can only mention these matters to you to let you know that the Committee is doing what it can, but at present it has nothing to put before you in the way of a formal report.

Mr. Jackson : May I ask a question in connection with this ? I want to ask whether it is not a fact that, owing to the exigencies of time, it has not been possible for the Committee to give adequate consideration to these matters, and whether the communications have yet taken place between the Executive Committee and the examining bodies?

Mr. Siddons : In one case, which has already been sent in, action was taken on instructions received from the General Committee. The General Committee did not actually pass the draft in its final form. There was not time. The examining body did not give us long enough. In the other case our recommendations have not been sent in. I used the word " or are just going to receive our proposals." The Committee is meeting to-morrow to consider the final form, and what is proposed for consideration is already before the members of the General Committee and will be finally settled at a meeting to-morrow.

Mr. Siddons (in proposing a vote of thanks to the President) said : I propose that a very hearty vote of thanks of this Association be accorded to Professor Hobson. He has been very kind to us. $\mathrm{He}$ is a very busy man, but he has found time to do a great deal to help and encourage us in the course of the last two years, not least by the kind words he has just said.

The vote of thanks having been passed unanimously,

The President said: In reply to your very kind vote of thanks, I have to say that it has been a very great pleasure to me during the last two years to be President of this Association, because I have had an opportunity of meeting people who perhaps have taken a wider view in many ways and who, at all events, have had an experience which differs from the experience of those I am most in the habit of meeting. I have learnt a very great deal by listening to what has been said at the meetings of this body, and I shall always look back to the two years that I spent in the chair with very great satisfaction. I feel that the experience has widened my outlook, and that I have heard the points of view of those who come in contact with a larger class of students than I have ever been brought into touch with myself. I shall always feel grateful to the Society for having given me an opportunity of getting an extended outlook on mathematical education in the country generally. 